\title{
Children's tactual exploration and copying without vision
}

\author{
AMEDEO D'ANGIULLI* and JOHN M. KENNEDY
}

Keywords: blind children; copying; guidance; sighted children; tactual exploration

\section{Introduction}

D'Angiulli et al. (1998) have reported that congenitally blind children have higher recognition rates for tactual pictures than blindfolded sighted children. However, blindfolded children who were guided not only attained levels of recognition equal to that of blind children (D'Angiulli et al., 1998), they also equalled the performance of blindfolded adults (D'Angiulli and Kennedy, 2000).

We present a further test of the hypothesis that guidance can facilitate children's tactile exploration. We invited blind children to explore tactile patterns and to copy three in detail. Copying performance of this group was then compared to the performance of two groups of blindfolded sighted children, one assigned to a guided-exploration condition and the other to an unguided exploration condition (self-guided exploration, not guided by the experimenter). Our stimuli were outline pictures of common objects. We observed empirically (D'Angiulli et al., 1998) that recognition rates per picture were below $45 \%$; furthermore, pictures unidentified by the blind were often unidentified by the sighted children. These two facts allowed us to match a blind participant with a sighted, asking them both to draw the same unidentified pictures. Consequently, the children could not explore a picture, find some way to classify it as, say, a person or a telephone, and then proceed to draw a different instance of the category. Copying, instead, had to rely on the knowledge gained from the pattern in the stimulus. Therefore, copying accuracy was used to determine which groups of children did in fact gain and reproduce information about the stimulus patterns, and in which conditions of exploration: would guided children gain more stimulus-pattern information than unguided, actively exploring children?

\footnotetext{
*Address for correspondence: University of British Columbia, ECPS, 2125 Main Mall, Vancouver, BC, Canada, V6T $1 Z 4$.
}

\section{Material and methods}

PARTICIPANTS

Seven congenitally totally blind children and two groups of seven sighted children were recruited as part of a larger research programme involving schools in Italy and Canada. The blind children were aged 8 to 13 and came from a school for the blind in Milan (Unione Italiana Ciechi). There were four girls and three boys. For three children, the cause of blindness was retrolental fibroplasia; the other children suffered, respectively, optic disc hypoplasia, bilateral congenital cataract, primary optic atrophy and congenital retinal degeneration.

The sighted children were recruited from a school in Toronto, and they were matched to the children who were blind by age and sex; the maximum age difference between a matched pair was 5 months. None of the children had used raised-line pictures previously.

\section{STIMULI AND APPARATUS}

The stimuli were eight raised-line drawings: face, bottle, cup, person, telephone, umbrella, scissors, key (all described in detail by D'Angiulli et al., 1998). Two other drawings (apple and shoe) were used in practice. The pictures were on Mylar sheets from a raised-line kit (Swedish Organization for the Blind, Stockholm).

Each age-matched pair was given the same presentation order of displays to explore and the same (unrecognized) stimuli to copy. The presentation order in the initial tactile (screening) test was randomized across subjects.

\section{PROCEDURE}

\section{Practice and recognition screening}

During practice, the children were tested individually, and blindfolded if they were sighted. They actively explored the apple and the shoe drawings. After the children named the objects depicted (by 
themselves or with aid), the experimenter guided their index finger around each practice stimulus twice.

In the screening recognition test, each guided exploration proceeded from a starting line clockwise around the figure, for about 30 seconds. In unguided trials, exploration started at the experimenter's signal but it was freely planned and controlled by the participants. The stimuli were presented one at the time. All participants were allowed up to 120 seconds of exploration and one response per picture; they had no feedback on their performance

\section{Copying task}

The experimenter selected three pictures that the participant had not recognized and asked the child to copy them as accurately as possible, for $5 \mathrm{~min}$ utes. Pilot experiments indicated that copying tasks based on a sample of three drawings were well tolerated and involved modest cognitive load for novices to tactual displays.

\section{Results and discussion}

Selection of the stimuli to copy was easily achieved post hoc, since high correlations among paired recognition scores (mean $z_{r} \sim 0.75$ ) indicated that pictures generally not recognized by one child were also generally not recognized by the matched counterparts.

Four judges - student volunteers from the University of Toronto - visually inspected the collected copies, and first attempted to name the object shown in each drawing. Successively they selected one of four object-name options for each drawing. In both procedures, each drawing was scored with 1 (recognized) or 0 (not recognized). The judges worked independently, viewed the copies in random order, and were unaware of details concerning recognition and copying experiments, or participants.
The total number of drawings recognized, divided by the number of judges, gave each participant a score (range: $0-3$ ) indicating how recognizable their drawings were, typically. The mean of these 'recognizability' scores was calculated for each group of participants (possible range 0-3 again). In the first naming procedure, the resulting mean was $1.04(\mathrm{SD}=0.74)$ for the blind children, $0.46(\mathrm{SD}=0.22)$ for the active children, and 1.18 $(\mathrm{SD}=0.76)$ for the guided children. In the second naming procedure, the resulting mean was 1.89 $(\mathrm{SD}=0.56)$ for the blind children, $0.86(\mathrm{SD}=0.48)$ for the active children, and $1.57(\mathrm{SD}=1.03)$ for the guided children. Polynomial contrasts indicated that the mean score for the unguided children was significantly lower than the mean score for both the guided and the blind, in the first naming procedure $(F(1,18)=4.91 ; P=0.039)$ as well as in the second naming procedure $(F(1,18)=6.73$; $P=0.018$ ).

In sum, the copies by the blind children were more recognizable and were rated as more accurate than the copies by the unguided children. However, the guided children copied as well as the blind children. Thus, the difference between blind and sighted children is in systematic tactual exploratory skills, since guidance enhances tactual exploration and, as a result, copying.

\section{References}

D’Angiulli, A., Kennedy, J.M. and Heller, M.A. (1998). Blind children recognizing tactile pictures respond like sighted children given guidance in exploration. Scandinavian Journal of Psychology, 39, 187-90.

D'Angiulli, A. and Kennedy, J.M. (2000). Guided exploration enhances tactual pictorial recognition in blindfolded sighted children: Implications for blind children. International Journal of Rehabilitation Research, 23, 319-20. 